\title{
Peer to Party: Occupy the Law
}

\section{by Melanie Dulong de Rosnay}

\section{First Monday, December 2016}

\begin{abstract}
In this paper I infuse political and legal theory with peer to peer decentralized design features. This experiment studies how property and liability, two core legal institutions attached to individual persons, react and can be transformed (like chemical elements) when applied a peer to peer, distributed design. This empirical and evolutionary approach of hacking the law, seen as a regulatory system, is then applied to the peer production of law itself, as a political advocacy method for achieving legal reform inspired by the peer to peer ethos.
\end{abstract}

\section{Keywords}

distribution, decentralization, law, peer to peer, hacking, peer production, property, liability, commons, responsibility, do-ocracy

\section{Contents}

Introduction

Peer to Peer, an Alternative Design Principle, and the Law

Distributed Property

Distributed Liability

Distributed Participation

Conclusion

\section{Introduction}

Cyberspace has renewed legal thinking (Lessig, 1999a and 1999b, Elkin-Koren and Salzberger, 2004). More specifically, peer to peer is a disruptive technology (Oram, 2001) for copyright law and cultural industries (Litman; 2001; Vaidhyanathan, 2005), and for law enforcement in general. Peer to peer transformative power can also be applied to knowledge (commons-based peer production, Benkler, 2006) and more broadly to society (Bauwens, 2005; Glorioso et al., 2010). A challenge to neoliberalism, peer to peer is also used purely for convenience (Cammaerts, 2011). Many applications have developed alternative communication paths around these protocols:

In recent years, governments around the world have turned off the internet or restricted internet access in moments of political unrest and during large-scale protests. But, what do you do if you are reporting on an event and can no longer communicate with others, send information back to editors, use Twitter to follow live updates, or access Google Maps to 
navigate your way through city spaces? How do you transmit information when the internet is not accessible?

Hong Kong Protests Propel FireChat Phone-to-Phone App

"Peer to Party" in the title of this article refers to the rise of peer to peer, not only as a technical infrastructure on the networks, but also as a sustainable political economy model for developing knowledge, goods and services, and as a set of alternative values in society. "Peer" is used both in the technical sense (as node in a peer to peer infrastructure) and in the social meaning (person hosting a node, using a peer to peer application, contributing to decentralized peer production, as defined by Dulong de Rosnay and Musiani, 2016).

In this paper, a jurisprudential analysis unfolding the theory of distributed architecture, I study the effect of applying peer to peer, defined as a technological design principle (Schollmeier, 2001; Reed and Sanders, 2008), to the liberal legal institutions of property, liability and democratic political participation. In this sense, beyond using technology as a tool of the law (Code as Law, Lessig, 1999), I propose to use technology as a tool for exploration and modelling of the law (following this methodology, see also Guadamuz, 2011, which uses network science to analyze internet law). Property and liability have been chosen as the most important legal institutions in private law and internet law, while political participation is the third element parsed through the peer to peer lens as an instrument of change and an actionable strategy for implementing distribution in the first two institutions.

Peer to peer fragmentation is particularly disruptive for the law because legal reasoning is accustomed to operate on subjects which are characterized by and uniquely attached to some spatio-temporal existence. At the core of our argument, this ontological difference between the nature of distributed technology and positivist legal thinking is also reflected in the gap between, on the one hand, capitalism, relying on identified entities (firms, workers) and, on the other hand, commons-based peer production, organized around non-fixed and uneven contributions. To link both ontological differences, the law is traditionally much more protective of the interests of capital (Capra and Mattei, 2015), with its identified owners, than of the commons, with a crowd of distributed peers, and the future generations which may contribute to and benefit from it. The contribution of this article is firstly to apply peer to peer to the theory of law, and also to suggest its transformative potential to reduce inequalities caused by the extreme concentration of capital and political power.

As a technology to be regulated (another mode of interaction between peer to peer and the law), peer to peer challenges the law, which usually applies to individuals, both in its reasoning and in its enforcement, at first copyright, considered as intellectual "property" [1], and intermediary liability, two central legal institutions discussed in this paper (Sections 2 and 3 ). Peer to peer is a reshaping element for the law (Lessig, 1999a, 1999b; Elkin-Koren and Salzberger, 2004; Elkin-Koren, 2006; Murray, 2006; Brown and Marsden, 2013), and a force able to transform other sources of power 
(Mansell, 2012), which can be applied in order to fragment legal categories, and distribute property (Section 2) and responsibility (Section 3). The rhizomatic distribution of actions among actors, as operated in peer to peer architectures which can be observed in distributed storage (Musiani, 2014) and community wireless mesh networks (Dulong de Rosnay, 2015), is prompting a reconceptualization of legal categories and a transformation of legal thinking.

The "Party" in the title refers to this technical fragmentation into parts (partire, divide in Latin). For lawyers, a party designates the legal entity participating in a contract, a lawsuit or any kind of legal action. Generally speaking, a party is an informal gathering of peers, possibly involving potluck and unexpected outcomes. "Peer to party" intends to set the tone for an admittedly rhetorical and idealistic celebration of peer to peer, even if peer to peer does not always challenge capitalism (Cammaerts, 2011).

In terms of scholarship, this paper stretches and applies the concept transversally, as a transformative element, and observes how the law reacts to it. The use of only pure peer to peer architectures at all communications levels (connectivity, encryption, applications, content, etc.) cannot necessarily be observed in "natural habitat" conditions. Some degree of centralization can be observed at some level most of the time. However, for the purpose of demonstration, I apply distributed architecture as an ideal type, mimicking experimental laboratory conditions in the natural sciences, in the same way that economists may rely on the supposed invisible hand of the market for some demonstrations.

"Occupy the law" proposes a sit-in approach to legal categories with the intention of changing the system outside a traditional political "party" by hacking the law, where hacking is understood as a social and cultural practice of resistance (Lin, 2004; Kelty, 2008; Berry, 2008; Barron, 2013; Coleman, 2013; Powell, 2016a). A number of blogs are using the expression "Occupy the law" to convey contestation and an alternative nature. I intend to use the expression "Occupy the law" in the same way as Wielsch (quoted in Steinbeis, 2012) to explain the transformative power of open licensing to achieve autonomy. Even if in this case the individualistic, author-centric conception of copyright law remains strong (Elkin-Koren, 2005; Dusollier, 2006; Barron, 2014), the copyleft hack allows us to use copyright law not to reserve, but to guarantee public access, reversing its original purpose.

Peer production of law and digital rights activism can be achieved through distributed political action (Section 4), relying on technology, platforms and participation (Jenkins, 2006), and proposing alternatives to vertical capitalism (Söderberg, 2013; Powell, 2016a) as supported by liberal political and legal institutions. Distributed political action, or do-ocracy, has been successfully applied at least twice in order to challenge established property rights and liability allocated to individual persons at the international law level. International agreements (ACTA, SOPA, see Powell, 2016b) and the WIPO Marrakesh Treaty to Facilitate Access to Published Works for Persons Who Are Blind, Visually Impaired or Otherwise Print Disabled (hereafter the 
Marrakesh Treaty) are recent global agreements affecting copyright and liability. The first was rejected and the second enacted, thanks to a distributed coalition of activists (including advocates of peer to peer networks), effectively disrupting the established legal order (Dulong de Rosnay, 2013).

\section{Section 1. Peer to Peer, an Alternative Design Principle, and the Law}

In this first section, I present peer to peer as a design principle and the challenges that fragmentation can pose to the law. Relying on the examples of community wireless mesh networks and distributed storage, I explain the difficulties of assigning liability. I then explain how the conflict is due to the ontological difference between the peer to peer model, and legal and liberal reasoning, which both depend on the concept of the individual for their own existence. After making this legal and philosophical point, I consider the legal precedents for peer to peer regulation in the field of internet liability, and how inadequate these have been.

Privacy and political activists are developing and using applications based on alternative technologies to protect their communication from governments and corporations, for instance with Tor anonymity software for browsing the internet, or Firechat, a local mesh messaging service which has been used during protests in the absence of a connection. Distributed architectures provide alternatives to centralized services which can be tapped, controlled or shut down by central authorities. Used in conjunction with encryption, these tools are helping demonstrators, activists, journalists and dissidents to circumvent surveillance. These alternative peer to peer communications technologies aim to address asymmetries of power with repressive regimes, corporate surveillance or law enforcement and intelligence agencies.

Distributed services are also used for practical reasons. Community wireless networks based on mesh protocols offer an alternative communication infrastructure, ensuring more or less resilient and performant access (Neumann et al., 2015) to the internet. They can be implemented in rural areas (Yarali et al., 2009), at festivals, after disasters, or in emergency situations (Dilmaghani, 2008). Besides, these grassroots initiatives are providing an alternative to expensive or unavailable commercial ISPs. In this sense, they constitute an infrastructure commons (Baig et al., 2015), with a locally governed, commons-based peer production of connectivity.

In the paper I presented at the Adam conference and published shortly afterwards (Dulong de Rosnay, 2015), I started to explore how peer to peer and its distribution design principle (Schollmeier, 2001; Reed and Sanders, 2008) reconfigures legal concepts and categories. In order to do this, I analyzed the techno-legal architecture of mesh networks and distributed storage (in the first version of Wuala, the service renamed Drizzle by Musiani (2014)) in order to explain the impact of the fragmentation of files and computing events on legal qualification, the intellectual opera- 
tion, performed by legal scholars, lawyers and judges, of assigning a fact to a legal category, and necessary for interpreting and applying the law.

Decentralization at various technical levels challenges legal enforcement because liability cannot be assigned to a single person, since files and actions are distributed among peers (see Marsden, 2013; Larsson, 2013):

Mesh networks are an especially resilient tool because there's no easy way for a government to shut them down. They can't just block cell reception or a site address. Mesh networks are like Voldemort after he split his soul into horcruxes (only not evil). Destroying one part won't kill it unless you destroy each point of access; someone would have to turn off Bluetooth on every phone using FireChat to completely break the connection. This hardto-break connection isn't super important for casual chats, but during tense political showdowns, it could be a lifeline.

How Hong Kong Protesters Are Connecting, Without Cell Or Wi-Fi Networks

In a fair and democratic justice process, individuals can be held liable for infringing the law directly or indirectly, by facilitating cybercrime, only if they can be identified and proved guilty. Law enforcement is accustomed to allocating tort to individual persons designated as liable or responsible for an action, not to unstable groups of peers (Dulong de Rosnay, 2015). Failing this, the law will try to target intermediaries (Elkin-Koren, 2006; Zittrain, 2006). Individual peers whose devices are part of an alternative network providing hosting, connection or browsing do not know what content they are incidentally facilitating the communication of. In the case of most community mesh or distributed wireless infrastructure, peers neither monitor nor store connection metadata or content exchanged. And in the case of distributed storage (in the first architecture of Wuala, analyzed as Drizzle by Musiani (2014), an alternative to cloud storage, data is first fragmented, then locally encrypted, only to be distributed among other users' hard drives as encrypted fragments which are not perceptible to the senses. Data is then duplicated. Redundancy enables retrieval at any time desired by the user, without all peers hosting encrypted fragments being connected. Users who are peers in the distributed hosting architecture are not identified by any central authority, for example the service developers. Only the original user who has encrypted her file for back-up purposes will be able to reconstruct and decrypt the file. No other user, developer or enforcement authority is able to control or see the file.

Fragmentation of data and actions jeopardizes the location-, time- and subject-based legal reasoning "where each object or right can be assigned to one actor." The legal method of attributing rights and responsibilities to identifiable persons does not apply well to "technically insignificant fragments" distributed among peers. And private international law relies greatly on the location of actions in order to determine both jurisdiction and applicable legislation. Concepts of "the author of an action, action and content or object are no longer tangible units, but aggregated, open-ended and evolving fragments" (Dulong de Rosnay, 2015). Peer to peer has the same effect on the law as algorithmic governance, as analyzed by Antoinette Rouvroy (2012), "bypassing" the notion of sub- 
ject and focusing on "temporary aggregations", also in contrast to liberal, tangible conceptions of persons.

The ontological difference between peer to peer fragmentation and legal reasoning unicity can be challenging for the (positivist legal) mind who is accustomed to the subjects of a law enjoying a state of permanence and unicity. The law is struggling with peer to peer because it usually requires the "actual existence of singular individuals" who are grounded in space and time, and this existence conditions the enforcement of the law (Karskens, 1997, pp. 40-41, with reference to Derrida's Force of Law, p. 996).

By extension, peers using and constructing peer to peer are injecting its ideology into a nonhierarchical, decentralized society corresponding to the holistic model (Dumont, 1983). This anthropologist and political theorist, a student of Mauss, analyzed individualistic and holistic modern societies, designating "an ideology which gives more value to the social totality as a whole and neglects or subordinates the individual as an independent given" (Dumont, 1983 p. 304). According to Dumont, the Political, as a fact and a category, does not emerge from interactions between individuals, but rather from the collective will of society as a whole. At this point it should be noted, or recalled, that the modern, liberal philosophical conception of law (Hobbes, Rousseau, Locke...) posits that legal principles "reflect the order of nature and are to be deduced or extracted from properties which are inherent to the human person considered as an autonomous, independent being" (Dumont, 1983, p. 97). Institutions of Property, Liability, and State derive from natural laws as foundations of the social contract. Utilitarian (Bentham) and positivist (Kelsen) schools, criticizing the justification and supremacy of natural law over positive law as a system of rules, are still relying on the premises of subjects when they criticize aspects of the source of law (morality and normativity) other than its application to subjects. Marx's critique of modern law and liberal ideology grounded in individualism (Fuchs, 2015) sees the origin of rights as being in community rather than in isolation: "Society does not consist of individuals, but expresses the sum of interrelations, the relations within which these individuals stand" (Marx, 1857).

In legal philosophy, legal personhood is a "legal fiction" (Bentham, 1997), a fact of the mind allowing the law to apply to non-human entities such as organizations, corporations, states, and to preserve their rights and responsibilities. The law has been able to deal with crowds, and with software agents; the law will be able to address Decentralized Autonomous Organizations even if these are not an established legal entity. Regulatory difficulties with regard to applications hosted on the blockchain arise from the technical distribution of the architecture (Mallard et al., 2014), not from their lack of personhood or from the automation of legal activities, which is nothing new (Guadamuz and Marsden, 2015).

Calling into question the persistence and adequacy of "individual legal entities [as] the basis of legal reasoning and the subjects of rights," I recognize that, even if the distribution phenomenon 
seems technically challenging, the concept of collectiveness and collective action is not, and has been addressed by the law. Indeed, several precedents in law have already been allocating responsibility and agency to persons for crimes performed by others (on murders committed within crowds, see the doctrines of common purpose (Unterhalter, 1988) and vicarious criminal liability (Kreit, 2007)). There is no need to be a person in order to be recognized in political philosophy or network science as having agency: this has been the case for collectives in networked social movements (Smiley, 2011; Bailey and Mattei 2013; Toret and Calleja, 2014) and for non-human agents (Teubner, 2006; Sartor, 2009). Therefore, the main theoretical obstacle to a legal grabbing of peer to peer is even more a matter of the absence of an individual agent than of the distribution or fragmentation of the action. Individual liability and shared liability have been recognized and implemented by law, unlike distributed liability.

Predictive social sciences, at the crossing of social movements and complex system science, are empirically proving social influence and re-enforcement, "interdependence between individuals," and "enabling the emergence of new types of self-organised collective behavior," following early cybernetists (Chavalarias, 2016). Blindly detecting future possible crime (Mohler et al., 2011) and acting upon it, as studied in the third section of this article on distributed liability, appears dystopian, and as unfair as the doctrine of common purpose making "One Person Liable for the Acts of Another" (Unterhalter, 1988).

Several legal hacks of peer to peer law have already succeeded in embedding collectiveness into law, as alternatives to neoliberalism, or at least to traditional market/state models: commoners' bundle of rights to shared property (Ostrom, 1990), water held as commons in Italy (Mattei, 2013; Carrozza and Fantini, 2016), Creative Commons rights under copyright segmentation (Elkin-Koren 2005), which will be analyzed in Section 2.

However, despite the existence of peer to peer law precedents demonstrating the ability of the law to address collectives beyond individuals, regulatory answers to data fragmentation and encryption have not been very effective. Anonymization technologies are used by both activists and cybercriminals. Tor, for instance, helps privacy-seeking dissidents and journalists, but also criminals, to facilitate the dissimulation of activities taking place on the Darknet (Bartlett, 2015; Minárik and Osula, 2016). The Silk Road was taken down by the FBI and resurrected just a few days later.

Targeting intermediaries is difficult for law enforcers because of the intermediaries' limited liability regulation enacted in the early 2000s. Thanks to the Internet Service Providers' intermediaries liability safe harbor, mesh network providers cannot be held liable for their users' infringement (Hatcher, 2007) if they promptly take down infringing content when notified. In the specific case of distributed storage, this would become irrelevant since the content is never published.

Regulators can try to outlaw peer to peer technologies, slow their development, or impair their implementation or use, which will lead to a chilling effect on innovative, legitimate usages. Vivendi 
Universal, a concentrated rights holder, proposed in 2006, during the transposition in France of the European Union Copyright Directive, that peer to peer file-sharing software be outlawed by the introduction of criminal liability for authors of software which could be used for copyright infringement purposes. These proposed amendments were invalidated as unconstitutional [3], since peer to peer can also be used for legal purposes.

Legislators can make it illegal to share a connection without identifying, securing or otherwise retaining metadata. The "three strikes law" in France and police operations in the US have targeted users accused of negligence in securing their wifi. Such policies of graduated response are not respecting the principle of proportionality and are harming freedom of expression (Guadamuz, 2014). Since IP identification is not fixed, and can be spoofed, such data cannot not be held to be sufficient information to trace an individual, or to identify her with certainty. The French Hadopi measure was revoked in 2013 , after only one suspension of connection.

Legislators can impose heavy monitoring and storage duties on internet access providers, for instance requiring them to keep a copy of both the identification and the connection traces of users. This was the case in Italy between 2005 and 2011. An antiterrorism decree [2] required owners or managers of internet access points using wireless technology to collect an identity document from persons using unsupervised public workstations for computerized communications. The process was extremely cumbersome, preventing open wifi, and in any case inadequate for regulating community mesh networks without a central manager or a contract which could indicate a legal relationship. When users are not registered or identified, and when their presence is unstable and not necessary for making available packages whose content they have no knowledge of, it is difficult to assign liability.

After identifying consequences, options and challenges of peer to peer for the law, and the notion of the legal person in legal theory and in internet regulation, the next sections consider more successful attempts to hack, or introduce distribution into law, and the concept of the individual person as a subject of rights (of property, see Section 2), of duties (or social responsibilities, engaging one's legal liability, see Section 3) and capable of political participation, action or activism (see Section 4).

\section{Section 2. Distributed Property}

This section analyzes three precedents of peer to peer: fragmented, distributed, or collective property among unidentified, evolving group of peers in legal history - the bundle of rights in common-pool resources, copyright and the public domain; Creative Commons licensing; and collective property in environmental law. As a methodology, I apply here the classical framework of 
"usus, abusus and fructus" as components of property rights, in order to better understand how property in terms of goods can be fragmentation, or in other words distributed. Another application of the framework, this time to big data, can be found in the work of Karanasiou and Douilhet (2016).

Property rights traditionally structure and limit access to, and enjoyment of, a good, including the right to exclude others, to alienate, or to sell it. Roman law recognized three categories: usus, the right to use the good; fructus, the right to grow or rent it; and abusus, the right to dispose exclusively of, destroy, or resell the good. These rights can be concentrated in the hands of a single owner, but various mechanisms allow the fragmentation of property among different users, identified or unidentified, actual or potential.

Property as a bundle of rights was conceptualized in the early 20th century by John Commons and the legal realism movement in the USA. Goods are not considered as the source of an absolute or monolithic natural right protected by State law, but rather as a set of social relations with various responsibilities, rights and duties.

Tangible and intangible commons operate a segmentation of access and use rights in relation to shared resources. Common-pool resources (Ostrom, 1990) and common goods (res communis) are an alternative to both exclusive individual property and to unregulated open-access, to tangible resources subject to exhaustion - what Hardin (1968) described as when tragedy of the commons may occur, or to res nullius, for instance space, as noted by Milun (2011), which can be used and enclosed by anyone.

Before the land enclosure movement, natural resources were considered as common property, with a bundle of rights (access, exploitation, management, governance, exclusion, alienation) distributed in accordance with different uses by the community: harvest, gleaning, pasture, grazing (De Moor, 2011). In her analysis of the bundle of rights and collective or shared property, Ostrom distinguishes rights of access to the common resource, removal (eg of wood from a forest), management (of rights to remove), exclusion (deciding who will have access rights) and alienation (right to sell or transfer other rights).

Intangible, non-rival goods are also subject to non-exclusive segmented property. As a second example, copyright organizes a limited monopoly of exploitation (itself fragmented among rights to reproduction, making available and transformation), while maintaining a series of limitations or exceptions: in time, with the public domain granting the use of rights to everybody, and in accordance with different activities, some remaining free for all (depending on jurisdiction: parody, citation, fair use, education, text and data mining, preservation and archiving by libraries, news 
reporting, etc.). The public domain has a different status, since it is possible to alienate it (abusus) when carrying out copyfraud, the private appropriation of public domain works, the copyright equivalent of counterfeiting.

This very innovative legal hack, providing a positive status to the public domain, and thus to the infringement of the public domain, with a sentence comparable to copyright infringement has been proposed in a WIPO study by Dusollier (2010) and reused in policy proposals (Communia Positive Agenda for the Public Domain and Communia WIPO Statement, 2012, rejected amendment to French Digital Republic bill, 2015 [4]) to preserve the public domain from exclusive appropriation. It protects not the rights of rightsholders, but the potential rights of possible future users to equally access and use the resource. The only sanction for misappropriation of the public domain in positive law can be found in Chilean law [5]:

(a) anyone who knowingly reproduces, distributes, makes available or communicates to the public a work belonging to the public domain [...] under a name which is not that of the true author

(b) anyone who claims or demands economic rights in works in the public domain shall be deemed to have committed an intellectual property violation.

The French minister for digital affairs proposed in 2015 protecting the public domain from individual appropriation practices which would lead to the removal of collective rights from the public (for instance, digitization of public domain works re-introducing exclusive rights) by allowing associations to sue on behalf of the public domain and stop exclusive appropriation. The proposal was not accepted.

This second example illustrates the problem arising from the absence of damage to an actual person (the author's rights have expired and there are no rightsholders to sue), as opposed to potential members of the public who could suffer from the enclosure of the work and be prevented from exercising rights which no longer belong to the rightsholders. The Chilean solution clearly and elegantly circumvents the issue by equating violation of the public domain with copyright infringement. However, the law does not indicate who is entitled to sue: the State or any party.

As a third example, Creative Commons (inspired by the FLOSS licenses model, GNU-GPL being the first) hacked copyright law by granting rights which fall under the limited monopoly of exploitation to the public. Licensees are a legal fiction, a group of non-identified potential persons who may or may not decide to exercise the rights and make them effective in the future. 
reproduction, or making available, and transformation, or making of derivatives. The right of access corresponds to the Roman category of usus. The right to reproduction, the right to make derivatives, and the right to commercial exploitation fall under fructus. The licensing scheme in its initial versions (1.0 through 3.0) also distinguished between the usus right to reuse without modification in a collection (not subject to optional limitation) and the fructus right to reuse in a transformative manner. Abusus, the right to exclude, is neutralized by the copyleft clause, requiring derivatives under fructus to be distributed under the same usus and abusus (access and reuse) conditions. Copyleft therefore distributes the fructus part of the property by protecting against abusus the future, potential rights of the public, as a collective, after an individual has exercised the right to make a derivative.

However, this fragmentation of rights, allocating some to the public while reserving some others, relies on copyright ownership and depends on the decision of the individual licensor (Elkin-Koren, 2005; Barron, 2014), who continues to enjoy in fine the rights of usus, abusus and fructus, and may decide to grant some to the group.

Rightsholders have the option to allocate fragments of rights under copyright under different conditions, granting some access (usus) rights to all. Licensors correspond, in the terminology of Ostrom, to providers who can impose conditions on authors, contributing editors and consumers/users and manage the various rights accordingly under the copyright bundle. They may reserve the commercial fructus rights and share with the public (or grant to the commons) only non-commercial, less valuable fructus rights. Exceptions under copyright ensure stronger and more stable collective rights to the extent that these are removed by law from the bundle of rights that the author may manage exclusively.

The ShareAlike option is "Approved for Free Culture Work", as granting the necessary freedoms required by the liberal open data, open education and open science movements. It also accepts sole attribution (CC BY), and voluntary, anticipated public domain (CCO), allowing commodification and proprietary enclosure with commercial usus, fructus and abusus. In the absence of a clause reserving commercial rights, the ShareAlike option (until the third version of the licenses) applies to the adaptation of a work, not to the unmodified work itself, which can thus be subject to content aspiration by predatory commercial websites whose business model is based on traffic and personal data exploitation rather than related to the resources being made available.

This side effect prompted efforts to develop "copyfarleft" licenses, introducing more finely grained distinctions so that commerce could be carried out by workers or cooperatives, where profits are redistributed, but not by companies which would extract and concentrate profits (Kleiner, 2007). 
Viera and De Filippi (2014) propose the development of a reciprocity clause "that restricts commercial usage according to how much the user has contributed to the common pool," requiring an actual ex-ante contribution by identified peers, instead of the copyleft provision opening possibilities ex post. The reciprocity model would re-introduce metrics and the identification of persons, unlike peer to peer architectures in which peers and contributions are not identified (contributing to storage or wireless could be recognized as a valuable contribution to the commons, but this would require identification, defeat anonymity, and possibly trigger liability, which does not play in favor of reputation nudge to encourage peer production). Copyfarleft and reciprocity correctives to commercial predation made possible by some Creative Commons options are designed for identified persons, not for evolving, unstable peers contributing to a peer to peer application. They are closer to shared property (a well-established practice in real estate [6]) than to actual collective property in which peers are not identified, as described in the first section of this article.

Collective groups of unidentified peers are addressed in environmental law legal hacks to property. Many States allow the purchase of the right to build, or limit possible usages (a fragment of rights) of a piece of land only to preserve it unbuilt for future generations. Voluntary servitudes, community land trusts, and conservation covenants or easements are among the various legal instruments available in civil and common law. Voluntary servitudes are designed to protect the environment, where a land owner transfers a fragment of her rights to the state or a non-profit intermediary for purposes of biological conservation.

Environmental law has created many hacks of the right to private property (Fernández, 2004; Owley, 2014). This transfer of property to achieve higher objectives leads to the allocation of many more rights than the fructus right to build to unidentified collective groups of peers which are not legal persons since they do not exist (an interesting example of the lack of legal personhood of unstable peer to peer distributed storage and mesh networks), and prevents abusus (which copyleft, copyfarleft and reciprocity copyright licenses have not yet achieved).

Also related to the protection of the environment as a commons, a legal hack under development that challenges the fiction of actual persons is the project for recognizing "ecocide" as an environmental crime in international penal law (Cabanes, 2015). This legal fiction would hold liable a company which could potentially damage the environment and harm future generations, by preventing them from exercising any rights to a piece of land, before pollution takes place. In this sense, the crime of ecocide resembles copyfraud, the enclosure of public domain works, since both conceptualize and recognize the potential rights of future unidentified groups of peers.

As Ugo Mattei notes (Capra and Mattei, 2015), the ideological construction of property as an 
individual freedom has done a lot of harm, since it has been used only to support extractive capitalist ideological hegemony, making it difficult to imagine other more generative purposes such as the transmission of rights to the next generations, to a fuzzy group of unknown peers, and difficult to write positivist legal hacks to support these alternatives.

This section has identified existing cases of distributed property. The distribution of rights to an object, be it tangible or intangible, is helpful for the conceptualization of commons-based collective property. The copyleft legal hack is a different allocation of the bundle of rights under copyright, as some rights are allocated in advance to future unidentified peers and the action of the license may be legally binding only at the time the right granted is exercised. In this sense, both the legal hacks of a copyleft license and environmental servitudes are transfers of rights in expectation of the resource growing and being used and fructified, but not abused (or enclosed) by future persons whom it would be impossible to contract directly at the time of the initial rights-owner's intention. The discussion in the next section moves to responsibility, and studies the effects of distributing this legal institution among an unidentified, unstable group of peers.

\section{Section 3. Distributed Liability}

This section considers whether it is possible or desirable to allocate socio-legal responsibilities or liability directly to collectives constituted of peers, rather than identified individuals. It examines a set of online and offline, small and large communities and discusses the actual meaning and the possible side effects of distributing liability - or responsibility, its equivalent in civil law - and its social translation. Distributed trust is then studied as a possible way of distributing liability, since the literal distribution of torts and collective forms of liability is not an option.

Distributed responsibility can imply collective monitoring, reporting and sanctioning of illegal uses, following Ostrom's Institutional Design Principle \#4: "Effective monitoring by monitors who are part of or accountable to the appropriators' and its complement", and \#5: "A scale of graduated sanctions for resource appropriators who violate community rules" (Ostrom 1990).

The ability of unstable groups of peers to endorse a duty of care and repair has been well identified and studied extensively in commons-based peer production: Wikipedia editors and administrators are developing and maintaining the resource. Their work to protect the commons from pollution by deleting copyright infringement, mistakes and vandalism, is intended to avoid the Wikimedia Foundation, a legal entity, being held legally responsible for hosting problematic content.

Musiani (2015) rightly points out that

...the collective dimension of this responsibility is also emphasized, and the collective consequences of individual infractions highlighted - regardless of whether the infraction is the storage of inappropriate content, the introduction of unreliable information or spam in a 
distributed search index, or a 'selfish' management of the bandwidth shared by a P2P streaming system.

But this responsibility is social, not legal. The peer production of distributed storage or mesh connection contributes to improved quality of service. The role of each peer is not crucial from a techno-legal point of view, so individual peers can disappear without endangering the viability of the system. They only carry a social responsibility as part of a collective (or as last node), since it is their collaboration which guarantees that the system will function effectively.

Crowdsourced surveillance, justice and policing can take place in services and communities which present a certain degree of centralization: for instance, Diaspora, the semi-distributed social network, may contact nodes or administrators hosting ISIS propaganda. But if crime cannot be seen or allocated to a person due to encryption or fragmentation, it is unlikely that a collective sense of responsibility will develop. Besides, collaborative policing without checks and balances could lead to exclusion of or discrimination of users based on their IP address, or for other illegitimate or disproportionate reasons.

The analogy of pollution monitoring for Wikipedia does not apply to distributed storage or connection, in the absence of an identified legal person or centralized technical architecture which would allow the detection of an infringement. There is no procedure for dealing with an infringement in a distributed service such as Wuala or a community mesh network. Community monitoring and self-regulation to ensure the legality of the content circulating cannot happen if no infraction can be detected (Dulong de Rosnay, 2015). Trying to distribute legal liability among peers as an answer to the legal challenge raised by distributed architecture is tainted by uncertainty and arbitrary unfairness, similarly to the targeting of intermediaries mentioned at the end of the first section.

Collective legal liability and distributed monitoring did not appear to lawyers desirable or feasible and these have not been implemented in licenses governing intangibles and inspired by the commons, and applicable to digital works or internet access. Neither Creative Commons licenses in their current version 4.0 nor the Pico Agreement, a license for community wireless networks, offer any warranty of the content or service provided. They even contain explicit disclaimers of liability. Should the content be infringing or the quality of service bad, they do not allocate responsibility to providers, to peers providing the work or to the service. Creative Commons licenses may be used to circulate (usus) and to build upon (fructus) infringing content, a source of pollution of the commons, of fragilization of the license grant, or of risk for potential licensees. I have argued elsewhere (Dulong de Rosnay, 2013) that it would be preferable to allocate (and thus distribute) responsibility to identified licensors rather than to unidentified licensees, which transmits potential problems along the chain. This would raise the value of works and services made otherwise available for free or at a smaller cost than commercial products. 
What kind of legal hacks could potentially distribute liability in the same way as copyleft dedication and such environmental entitlements as "advanced donations" for property? Could collective mechanisms of trust and reputation permit, on the one hand, the avoidance of damage? And, on the other hand, could insurance or mutualization allow a sharing of risk in the case of damage without the chilling effect of allocating liability to some or all individual peers, or to a group of peers? Would they be applicable and enforceable with respect to an unidentified, evolving group of distributed peers?

A precedent for the implementation of distributed trust actually fragmenting the risks, the legal liability and the social responsibilities within a group of peers can be found offline. An example of an online peer to peer platform for an offline regulated activity is the development of peer to peer insurance policies for cars. Guevara, in Brighton, UK, allows peers to pay a pool contribution to cover claims, and an insurance fee in the case of additional claims. Savings lower the insurance renewal fee. Groups of friends can be constituted in order to customize the insurance fee. Pooling in a group means that the risk is distributed among members: the peers' financial contributions should be redistributed to the faulty peer becoming liable or suffering damage, or to everybody if all enjoy safe and lucky driving. This model of distributed responsibility requires voluntary pooling and trust among a small group, closer to the original Ostrom model of small-scale commons. A detailed case study could confirm organizational patterns and factors of (un)sustainability.

Arbitrary pooling would bring back the unacceptable models of allocation of responsibility presented in Section 1 with regard to murders. A comparable commons-based peer production case study, involving a local community organized through an online platform, can be found among groups of consumers supporting a local farmer or cooperative of producers who provide bulk delivery on subscription, and accepting smaller or less diverse weekly baskets in difficult times. AMAPs (Associations for the Preservation of Traditional Farming) have a charter, which follows Ostrom's Institutional Analysis Design framework (Lamine and Rouchier, 2014), with arrangements demonstrating "mutual confidence and asymmetrical solidarity" (Mundler, 2007).

On a larger online scale, instances of Trust Web tokens and rewards of peer to peer trust remain mostly individualistic. Smart Contracts record the assignment of (individual) rights to (individual) parties. Cryptocurrencies similarly rely on distributed technology to perform legal actions such as authentication, but they ultimately embed individual control. Mining, the operation by which transactions on the blockchain are verified, is designed in a technically distributed manner, without a central trust intermediary, but this computer operation is not concerned for honesty or the subsequent absence of damage, source of tort or liability. Trust in the code is a recording modality, and does not equate to trust in actions taking place after the authentication of the transaction, 
whether or not they violate it. Violation of trust, as in any anonymous scheme, is not unknown, and actual distributed trust may require re-intermediation, involving some level of re-centralization (Mallard et al., 2014). This would facilitate regulation, but remove the theoretical question of the existence and potential effect of distributed liability in the first place. It could also mean that responsibility cannot and should not be distributed, if it could have the effect of diluting the sense of accountability and moral responsibility. This is a genuine legal concern that arises from psychological studies: enhanced perception and hyperagency, which occur after human or cognitive enhancement, but can also be applied to the situation of peers when this is magnified by peer to peer applications, could change the perception of blame and responsibility and decrease social solidarity (Danaher, 2016b, quoting Nagel, 2010).

Considering viable examples of distributed trust observed in peer to peer car insurance and food cooperatives, and developing voluntary collective mechanisms of solidarity to cope with damage may be a financial and sustainability requirement for developers or visible nodes among collectives which risk facing arbitrary sentencing, depending on which peer or intermediary could be held liable. It would be a positive conception of distributed responsibility, a cooperative management of tort, a voluntary sharing of risks - not a denial of individual liability through the dilution of personhood, but a re-enforcement of trust through local groups or community nodes. Distributed trust (Chatwick, 2007) can also have a deeper political meaning, which is the subject of the next section.

\section{Section 4. Distributed Participation}

As the third and last institution to which the prism of peer to peer design is applied, distributed political action and participation is analyzed in this section both as a method and as an objective in opposition to the concentration of copyright and of liability for online infringement. Ultimately, the law can be seen as an operating system developed by peers, as the product of peer production, and as a commons itself able to support the commons in other fields of policy-making. I discuss here the case of the epistemic Access to Knowledge community, which relies on do-ocracy and on a peer to peer flavor of democracy as distributed political action.

Electronic democracy, mediactivism, technoactivism, network activism or hacktivism is a broad and well-established academic field (see, among many others, Bodó and Gunkel, 2005; Bodó, 2014; Coleman, 2012; Milan, 2013, Powell, 2016b). Collectives embedding the most distributed architecture in their methods and governance include Anonymous (Coleman, 2015), to a lesser extent the Pirate Parties (Burkart, 2014), and self-reportedly La Quadrature du Net (Digard, 2011). The use of specific tools is transforming participation and agency (on the use of wikis, see Feenberg, 2014; on 
freedom technologists, see Postill, 2014; on liquid democracy, see Cammaerts, 2016; see also tools used in the construction of local European experiences of distributed politics such as Podemos and the pilot cities of the $\mathrm{D}$-Cent European project).

It is within the context of these social movements that I have searched for the nuance of distributed participation, and the space where peer to peer architecture is infusing political engagement, and that I discuss here its methods and effects. And it is within the overlapping contexts of digital rights (Postigo, 2012), access to knowledge (Kapczynski and Krikorian, 2010) and freedom of information (Beyer, 2013) advocacy movements - a "heteroclite coalition" (Dulong de Rosnay, 2013), that I look for advocacy campaigns resulting from distributed political activism and aimed at further distributing rights under copyright to the public, or at avoiding a blind distribution of responsibility.

Several examples illustrate this model: the vote to approve the Marrakesh WIPO treaty after the constitution of an ad-hoc distributed community, which is considered below, and the withdrawal of international agreements such as ACTA and of national legislation such as SOPA and PIPA, which is mentioned more briefly. Peer to peer, and digital technologies in general, are both a means and an end, a tool and an objective. The experiment and the rhetorical metaphor of peer to peer is therefore applied twice, reflexively, as a method and as an objective, as a cause to support and as an identity to defend. The effect of these two experiences of peer to peer policy-making has been to distribute rights under copyright, as opposed to maintaining a concentration of all attributes of the bundle of rights in the hands of rightsholders, and refusing the monitoring of online activity and the allocation of responsibility for infringement to users and intermediaries. The vote and the dismissal of these international treaties and agreements are constitutional moments for a diverse and loose advocacy coalition that is collaboratively developing a policy agenda around shared values of access, using digital participatory tools and culture. After "political agnosticism" (Coleman, 2004), hackers achieving politics through code (Berry, 2008, Chopra, 2010) or going one step further and engaging in politics are importing principles and free software tools that are used to write code (Broca, 2016, on La Quadrature du Net).

As the third and last case of a peer to peer legal or political institution discussed in this paper, peer to peer politics relies on distributed, apparently uncoordinated actions of peers emerging from epistemic policy-making communities characterized by hybrid organization that is "Fostering Distributed Trust Across Horizontally Linked Citizen Groups" (Chatwick, 2007). These online communities are open, undefined and transnational. Their mapping (social connections and geographic location) may resemble that of a mesh network, without central coordinators, often without personal credit (comparable to attribution rights under copyright) for successes, and without mechanisms of accountability (the equivalent of liability) for failures [8]. This decentralization applies to grassroots citizen protest movements (such as Occupy, Arab Spring, 
15M, Nuit Debout).

Access to Knowledge - a networked distributed community - managed in 2013 to change international law. For the first time a binding international instrument (the Marrakesh Treaty, see Fitzpatrick, 2014; Dixon, 2014), which did not give more rights to rightsholders (thereby centralizing rights and value), but distributed these by introducing a new exception to copyright was voted in. The intensity of discussions was due to the fact that the target community, blind and visually impaired persons, was not a fixed class of persons easy to identify, such as librarians, students or other beneficiaries of exceptions under copyright. At the end of the negotiations, the exception was not granted directly to the group of beneficiaries, but to identified intermediaries. Non-profits working with blind and visually impaired persons became entitled to produce accessible versions (e.g. Braille) of works available in other languages.

This was the first major success at the international law level of the Access to Knowledge community, a coalition constituted by countries of the global South and NGOs developing and promoting a positive political agenda (Kapczynski and Krikorian, 2010). This community brings together classical NGOs, professionally recruited civil servants, experts, consultants and academics, and informal groups who do not participate in the formal negotiations, but contribute to establishing the political agenda and mobilizing citizens. This networked form of digital activism is led by a very small number of actors without traditional forms of democratic representativity or accountability, building legitimacy through do-ocracy, a method which described below.

A very small number of diverse actors have changed both power relationships, this being the first time that the public interest has been taken into account in the formulation of a treaty: for Dixon (2014), this is a "Discursive Intervention in International Intellectual Property Policymaking [in which] Developing Countries and Civil Society Employ Text to Challenge and Change the Status Quo." Advocacy strategies are based on decentralized digital networking, with actors gaining legitimacy through do-ocracy. This loose group of networked peers and NGOs brought together communities which were previously separate (Intellectual Property academics, librarians, universities, tangible and digital commons, Free, Libre and Open Source Software (FLOSS), open data, and open science movements), collaborating with countries of the South (emerging from the Development Agenda Group at WIPO, Brazil, Argentina, joined by Chile, Algeria, India and South Africa, similar to the Group of 77 at the United Nations) to develop a positive policy agenda, culminating in the vote to approve an international treaty granting rights to associations providing books for blind and visually impaired people.

This distributed group succeeded in reversing the paradigm of ever more Intellectual Property. It is a counter-power to Group B, including the United States, the European Union and other developed 
countries with strong knowledge, entertainment and publishing industries, such as Canada or Switzerland, whose economies rely on Intellectual Property (copyright and also patents). The consequence of the rise of distributed politics was a switch of paradigm to evaluate Intellectual Property: IP for development (of access to education, science, innovation, culture) may replace development of IP. The vote on a treaty which for the first time grants enforceable rights, in the form of exceptions to exclusive rights, constitutes a first hack into international copyright law based on centralized property.

This distributed community borrows the name of the Access to Knowledge conference series started at Yale: researchers in law, economics, sociology, physics, biology and political science, lawyers, librarians and NGO activists for the right of access to medicine, patents, research, education and culture, free software programmers, college students involved in free culture, farmers freeing seeds, digital commoners and voluntary sharing advocates (peer to peer software, technobrega, Creative Commons, Open Access, Freedom of Information, open data movements) managed together to develop an agenda which was carried by the Development Agenda Group all the way to the vote on the Treaty in 2013.

A first federative moment for this community occurred in 2005 , with the drafting of a shadow treaty for Access to Knowledge which had the structural effect of creating a collective political program for the definition of flexibilities and exceptions to Intellectual Property for access to education, culture, medicines or patents. Their motivation and purpose is to achieve an exit from the framework of cultural and economic concentration and domination by a neocolonialist, neoliberal order set by the North - mixed with arguments for human rights and libertarian arguments for freedom and return on taxes. Mixing leftist and rightwing values, the community maintains a coherence in its definition of objectives for more freedom for users and more rights for peers.

The a2k coalition at WIPO can be described as an epistemic community (Haas, 1992), a transnational policy community (Stone, 2008), or a transnational epistemic community (Dobusch and Quack, 2008; Barron, 2014; Mansell, 2012). It brings together NGOs (Lee, 2012; Polaud, 2012) and civil society (Bangasser, 2009), working with developing countries (Dixon, 2014) in a loose coalition (Florini, 2008). I apply here the concept of do-ocracy, which comes from the hacker culture, in order to describe the work of this community.

The hacker governance culture (Kostakis, 2015) developed the notion of do-ocracy, a peer to peer variation on democracy, a hacking method for "getting things done" (part of this section builds upon some earlier work of mine on this topic, see Dulong de Rosnay, 2013). Do-ocracy, or distributed political action, has been put into action by collectives of somehow unidentified (either truly anonymous or not really famous) peers in order to influence and redirect copyright and thus, in a sense, to successfully hack the law. 
Derived from the Free Software and Open Source Software movement and inspired by the ethics of hackers and the Do It Yourself method, do-ocracy is an organizational principle based on decentralization and action. Actors choose their own roles and, by executing tasks, gain responsibilities, expertise, legitimation and social capital through their work and competences, rather than through election or a more traditional elite socio-professional selection process.

A do-ocracy is an organizational structure in which individuals choose roles and tasks for themselves and execute them. Responsibilities attach to people who do the work, rather than elected or selected officials. (CommunityWiki)

Do-ocracy: If you want something done, do it, but remember to be excellent to each other when doing so. (Noisebridge wiki)

A do-ocracy (also sometimes do-opoly, which is a more obvious pun on 'duopoly') is an organizational structure in which individuals choose roles and tasks for themselves and execute them. Responsibilities attach to people who do the work, rather than elected or selected officials. (Wiki of the Open Source Geospatial Foundation)

Do-ocracy (Mischform aus engl. Do und Democracy) ist eine Organisationsform, in der Individuen selbstständig ihre Aufgaben aussuchen und ausführen. Verantwortlichkeiten liegen bei den handelnden Personen und nicht bei gewählten oder bestimmten Posten. Ursprünglich wurde dieses Modell von der US-amerikanischen Libertarian Party von Sean Haugh und Michael Gilson-De Lemos vorgestellt. Es wird heutzutage vor allem von der Open Source- und Wikibewegung benutzt. Auch unter Teilnehmern des Burning ManFestivals ist es beliebt. (Wikipedia Deutsch)

Apart from its occurrences in geek vocabulary for hacking projects, the word do-ocracy was used to self-describe the political action of la Quadrature du Net (Digard, 2011: "the capacity of action entails decision") and of Anonymous ("that means rule by sheer doing: Individuals propose actions, others join in (or not). There's no one to grant permission, no promise of praise or credit, so every action must be its own reward." (Norton, 2012)). It has been mentioned in two academic books, first to describe the Burning Man organization (Chen, 2009) and then the chaotic and unstructured actions of individuals in the video remix culture (Birk, 2014), as well as in a paper on political participation in the Netherlands (Verhoeven et al., 2014). The latter relates it to active citizenship and participation - "active citizens who wish to contribute to the public domain by simply doing things instead of voting, deliberating or negotiating" - and cites papers by Wijdeven on "doe-democratie" (do-ocracy in Dutch) in local cities and therefore outside the hackerspace. A symposium entitled Can do-ocracy deepen democracy? was held in the Netherlands in 2012, and a Dutch governmental document refers to the method (Ministry of the Interior and Kingdom Relations, The Netherlands, 2013).

Again in this third case, the method of distribution has also been applied beyond information policy and intellectual property, in environmental activism, in order to avoid private appropriation leading 
to exclusion and pollution. Among the instances of do-ocracy found in Google Scholar, one is indeed to be found in environmental activism.

Such parallels are not surprising, since both movements are trying to protect digital and natural commons from enclosure; intellectual property is the second enclosure movement, according to Boyle (2003), who also pleads for the emergence of an information economy politics and advocacy movement comparable to the environmental movement. This analogy can be further developed: like the environmental movement, it owes its rhetoric and argumentation to the disciplines of ecology and welfare economics (Boyle, 1997), the digital rights movement political interventions in IP, and IT legal controversies arising from the disciplines of computer science and network systems, coupled with the political economy of information (itself a mix of communications, legal and economic studies). Boyle (1997) rightly points to the opposition between the author-centered model of property rights and "the blindness to the importance of the public domain," where the bundle of rights is effectively distributed.

A synonym of do-ocracy, doing by acting, is actocratie, as seen in Dutch (actocratie), on a mailing list of the Pirate Party Netherlands, used to designate people who do something and therefore become natural leaders of a group also including people who do nothing. Mathias Klang explains actocracy as a form of governance observed in "voluntary net-based organizations", where all members have the possibility of participating, even if sometimes lengthy discussions can prevent action and consultation favors inertia if no consensus is reached. A hackerspace in Oslo explained how it is governed as an actocracy:

...they that do - rule. If you would like to organize an event, build something or improve upon the space, just do so. A community of software developers applies the principle to the decisions related to product development: 'Ultimately whoever ends up doing the work should have final say.'

The expression is also used outside geek culture, for example in a mountain rescue team, where decisions are taken by the most experienced and skilled persons, whose voices are given greater weight:

I know a guy who has worked on a mountain rescue team. The work is exacting and dangerous, involving cross-country travel in hazardous conditions, rapelling down steep slopes and hauling injured people back up, and so forth. The teams have to make difficult tactical decisions at times, and the decisions are made by those who participate and do the work. He calls it 'actocracy' - those who act get to make the decisions. So, within the team, those who have been on previous missions participate in deciding; and the opinions of those who have more experience and greater skill and competence - as judged by others on the team - carry the most weight. There is clearly a hierarchy of status, but the status is based on a track record of past performance.

This horizontal, distributed form of democracy, where power is derived from action, and its working differ from the vertical form of democratic representativity through elected people to whom power is delegated: "In an actocracy the person prepared to do the work actually steers the movement." A 
tweet by @kyrah from 2010 defines actocracy as follows: "let the one who holds the brush decide the colour of the wall she paints." "Inversion of control structures" is what characterizes this form of power. This model and its lengthy deliberations have been seen again in assemblies of the movements of Nuit Debout in 2016, the Indignados, Occupy and the Arab Spring: "The Tunisian Revolution was all about actocracy (...), nothing was planned" (El Mekki, 2012).

Do-ocracy entails self-organization, a de-structuration of the contestation space, a community with a variable geometry configuration, a non-institutional decentralization of advocacy with an ad-hoc coalition, or a flat, horizontal model for political participation.

Even if it appears as distributed, personal re-centralization can occur around more mediated leaders in a do-ocracy. Occupy in the USA, 15M in Spain and Nuit Debout in France are represented in the media by academics. The Marrakesh Treaty owes a lot to a few actors professionally recruited in the classic manner. It is noteworthy that the diplomatic negotiations at one of the final WIPO conferences, before the vote on the treaty, saw two law professors representing the United States, who were opposing the treaty, opposing the delegate of Nigeria, also an American law professor, who had double citizenship and was able to represent both the voice of the South and the Access to Knowledge (a2k) movement, a broader community which does not attend WIPO diplomatic conferences, but which participated in the agenda setting. Indeed in 2013 , for the first time in the history of international copyright, a treaty was voted upon that did not extend the prerogatives of rightsholders, but gave rights to the public, specifically blind and visually impaired people and the associations representing them.

The a2k coalition is connected to the movement for digital rights which opposed the AntiCounterfeiting Trade Agreement (ACTA), rejected by the European Parliament on 3 July 2012, and which supports a free and open internet. They also rely on the efforts of a very few individuals (showing a recentralization), whose legitimacy has been questioned by the civil servants in charge of developing ACTA at the European Commission (or the Hadopi "three-strikes" law in France) as representing only themselves.

They actually rely on a broader distributed community, using, for instance the PiPhone, a free software tool designed to massively call Members of the European Parliament over the phone, a mode of political activism MEPs fear (interviews of MEPs by the author, 2012-2013), in addition to more traditional participation in demonstrations (to defeat ACTA, in Poland). The Pirate Party has been refused the status of observer available to a2k and IP NGO lobbyists at WIPO, but has had two Members of the European Parliament for the past two parliamentary terms. The use of online participation tools has been studied (see Cammaerts, 2008, on multi-stakeholders and mobilization for a multilateral OECD treaty on investment; Powell, 2016b on opposition to SOPA, PIPA, ACTA, 
and Tréguer, 2013, on digital activism as hacking of public space). Only La Quadrature, Telecomix and Anomymous, groups with a computer hacker culture, have directly identified themselves with do-ocracy.

This form of political activism, associating the use of information technology and do-it-yourself culture, differs notably from other forms of representativity and power sources, and it is legitimate to question its legitimacy:

Democracy. In a democracy, everyone has a say in what gets done. In a do-ocracy, everyone does jobs that they think need to be done, without everyone's input.

Meritocracy. In a meritocracy, the most qualified people for a job are selected for that job. In a do-ocracy, whoever does the job gets it, no matter how well they're qualified.

https://communitywiki.org/fr/DoOcracy

The motivations are social recognition (as with classical political engagement) and acquisition of competences (like free software contributors). Participation can cause frustration for those who have the expertise but not the time, or for those who carry out dull work and can be discouraged. There is a risk to sustainability if the community's most active leaders leave, and a risk of despotism on the part of actors who, like autocrats, can control the discourse because they occupy the space.

But, more importantly, do-ocracy, like meritocracy, technocracy, democracy of experts, epistocracy (Eslund, 2013), and algocracy (rule by algorithms, see, Danaher 2016a), deeply question democratic representativity and can lead to a re-concentration of powers without accountability in the hands of those who have most time, and an abandonment of issues which are of least interest to the do-ocrats. This can lead, for instance, to an over-representation of technical topics, connected to young, white, educated male over-representativity (e.g. the gender and South gap in Wikipedia articles). Similarly, the implementation of distributed social currency as an incentive for political participation is questionable if the practice of receiving tokens for mining is exported as a way of encouraging contributions on peer to peer political platforms, as discussed by Roio et al., 2015.

In the previous section, I consider the distribution of trust as a possible option for distributing liability. Therefore, following the experimental protocol, let me try to apply it again to policy-making. The ethical implications for trust and political participation of the design of a distributed participation and policy-making platform in which "the proof that a member in the system is endowed with coins as a reward to an action in the real world while abiding to community rules and enhancing collective values" should be discussed. Implementing reputation tokens and rewards for 
participation (as in the Icelandic pilot for YourPriorities, see Roio, 2015) has consequences for democracy. It is an interesting solution for mitigating the sustainability challenges of distributed politics, but the risk of users submitting a large number of useless or repetitive contributions (to further hack the system and get free swimming pool tokens) may impact political diversity and representativeness (peers with more time and more limited financial resource, i.e. students, are likely to contribute more, and balance the possible over-representation of paid lobbyists or political activists who might otherwise contribute more to traditional policy consultations) and should be mitigated.

The distribution of participation is often designated by transparency, or openness (as in free and open source software), and presented as an ideal supposed to allow each and every voice to participate (with alluring labels such as "Open Source Democracy," see Rushkoff, 2003). It is not necessarily desirable to transpose these features into politics, and the present analysis of distributed politics should avoid both the idealization of changes induced by the distribution of agency and "a politics totally enmeshed in computational metaphors" (see Tkacz, 2012, who recalls that these values are claimed by the entire political spectrum, from libertarians and to neoliberals, and Hayek's plea that "decentralisation becomes imperative" to post-marxists and leftwing activists). In order to mitigate the lack of accountability of distributed participation and provide a democratic anchor for an otherwise libertarian do-ocracy, Verhoeven et al. (2014) suggest that pragmatist criteria should always be in place and depending of the type of institutional involvement one may add classical criteria. More concretely, this means thinking about symbolic representation, horizontal story based forms of accountability, and looking at reciprocity instead of equality.

Again, as for liability and distributed trust, literally distributed participation is not the most mature application of the framework of peer to peer to a legal institution and shows the limits of an overly techno-utopian view of distributing everything.

Experiences of distributed policy making show that an alternative legal order can be produced by competent peers, since lobbying capacity has been achieved by access to knowledge, pirates and citizen users' rights activists. Effective competitors of established advocacy groups have managed to transform the law with regard to redistribution and fairness. But transaction costs are high. The constitution of an ad-hoc coalition in favor of changing the law requires capacity building and politically relevant proposals linked to physical capacity and social capital. A systematic distribution of everything raises huge concerns of dilution of accountability. More research is needed to investigate the promising area of distributed trust, based on reciprocity and solidarity, and to solidify distributed property by also including reciprocity and taking future generations into account, as environmental legal hacks have demonstrated. 


\section{Conclusion}

This article presents another mode of interaction between law and technology, by demonstrating how distributed architectures can be embedded in law as a design feature. Peer to peer distributed design is applied as an experimental method to transform the three legal institutions of property, liability and political participation. Applying a peer to peer design to legal institutions has the potential to make them fitter for the commons. Promising examples of legal hacks, both online and in environmental law, are studied. The results of the experimental protocol explain how the peer to peer lens can make legal institutions fitter for the commons, while showing some of its limitations. Developing policy alternatives to individual property and liability, in the form of the legal hacks presented here, is an effective way of challenging the dominant ontology of law and of capital, both grounded around the concept of the liberal individual person which is challenged by peer to peer, and of distributing rights and responsibilities instead of concentrating wealth, liability and powers.

\section{Acknowledgements}

I would like to thank Francesca Musiani and Cécile Méadel, the co-editors of this special issue, for continuous support and discussions about decentralization and distribution since the inception of the Adam project in early 2010. I am also grateful for exchanges within the European P2Pvalue and the netCommons projects, which helped shape my ideas. This research is now partially supported by the European Commission, H2020-ICT-2015 Programme, Grant Number 688768 "netCommons" (Network Infrastructure as Commons).

I also gratefully acknowledge the comments received from reviewers and at presentations of earlier drafts of portions of the paper, and from colleagues at the LSE Department of Media and Communications, the LSE Law and Communications Research Network, Bournemouth and Bocconi Law Schools, the Marcel Mauss Institute at EHESS, and Gikll 2015. The notion of doocracy emerged in papers I presented at the French and the International Association for Political Science conferences in 2013 and 2014, and survived thanks to the interest of Anja Adler and Bart Cammaerts. Special thanks to Chris Marsden for coining the word "party" in the title of this article.

\section{About the Author}

Melanie Dulong de Rosnay is an Associate Research Professor at the Institute for Communication Sciences, National Centre for Scientific Research (CNRS) - Paris Sorbonne - UPMC, Paris, France.

E-mail: melanie [dot] dulong [at] cnrs [dot] fr 


\section{Notes}

[1] Copyright differs from other forms of ownership or property of tangible items. Nevertheless, I keep the controversial label of "intellectual property" in order to justify the choice of legal institution challenged.

[2] Italy, Legge 31 luglio 2005, n. 155 "Conversione in legge, con modificazioni, del decreto-legge 27 luglio 2005, n. 144, recante misure urgenti per il contrasto del terrorismo internazionale," pubblicata nella Gazzetta Ufficiale n. 177 del 1 agosto 2005. http://www.camera.it/parlam/leggi/05155I.htm

[3] France, Conseil Constitutionnel, Loi relative au droit d'auteur et aux droits voisins dans la société de l'information, Décision n²006-540 DC du 27 juillet 2006, Recitals 54-57. http://www.conseil-constitutionnel.fr/conseil-con..cision-n-2006-540-dc-du-27-juillet-2006.1011.html

[4] France, Article 8 of the Digital Republic bill, 2015 (not adopted) https://www.republique-numerique.fr/consultations/projet-de-loinumerique/consultation/consultation/opinions/section-1-les-communs/article-8-definition-dudomaine-commun-informationnel

[5] Chile, Law No. 17.336 on Intellectual Property, Article 80 as enacted by Law 20,435, Article 1, No 10, D.O May, 4, 2010. http://www.wipo.int/wipolex/en/details.jsp?id=797

[6] Property between a limited number of identified peers is widespread in real estate law (for instance access one week a year with possibility to rent in a holiday resort, or shared occupation of a room between two persons working during the day and during the night in Mumbai). Co-property will distribute property, but also duties or servitudes to a distinct space (the ground floor of a building).

[7] Again reluctantly, I use the expression Intellectual Property because I mean not only copyright, but also patents, since access to medicines also means a distribution of rights.

[8] This does not imply that centralized political action in representative democracy has an effective mechanism of accountability in case of failure (corruption, lack of respect for the program), since re-election is not correlated with any form of assessment of success.

\section{References}

Roger Baig, Ramon Roca, Leandro Navarro, and Felix Freitag. 2015. "Guifi.net: A Network 
Infrastructure Commons." In Proceedings of the Seventh International Conference on Information and Communication Technologies and Development, p. 1-4. ACM Press.

Saki Bailey and Ugo Mattei, 2013. "Social Movements as Constituent Power: The Italian Struggle for the Commons," Indiana Journal of Global Legal Studies: Vol. 20: Iss. 2, Article 14.

http://www.repository.law.indiana.edu/ijgls/vol20/iss2/14

Bangasser, S. (2009), Multilateral Institutions and the Recontextualization of Political Marketing: How the World Intellectual Property Organization's Outreach Efforts Reflect Changing Audiences. MEDIA@LSE Electronic MSc Dissertation Series.

http://www.Ise.ac.uk/media@Ise/research/mediaWorkingPapers/MScDissertationSeries/Past/Bang asser_final.pdf

Anne Barron, 2013. "Free software production as critical social practice", Economy and Society, 42(4), pp. 597-625.

Anne Barron, 2014. "Intellectual property and the open (information) society", in: David, Matthew and Halbert, Debora, (eds.) The SAGE Handbook of Intellectual Property. SAGE Publications, London, UK, pp. 4-27.

Jamie Bartlett, 2015. The Dark Net. London: Windmill Books.

Yochai Benkler, 2006. The Wealth of Networks: How Social Production Transforms Markets and Freedom, New Haven, CT: Yale University Press.

Jeremy Bentham, "A Fragment on Ontology", "Essay On Logic", and "Essay On Language", dated 1813-14, with additions 1821, in The Works of Jeremy Bentham, published under the superintendence of his executor, John Bowring, 11 vols. (Edinburgh, 1838-43), VIII, pp. 193-338. Henceforth Bowring. ('Of Ontology', translated and republished as Jeremy Bentham, 1997. De l'ontologie et autres textes sur les fictions, Éditions du Seuil.

Michel Bauwens, 2005. "The Political Economy of Peer Production". CTheory 1. http://www.ctheory.net/articles. aspx?id=499.

David Berry, 2008. Copy, rip, burn: The politics of copyleft and open source. London: Pluto. Jessica Beyer, 2014. "The Emergence of a Freedom of Information Movement: Anonymous, WikiLeaks, the Pirate Party, and Iceland." Journal of Computer-Mediated Communication 19 (2): 141-54.

Mette Birk, "The Panopticon of Ethical Video Remix Practice", in Navas, Eduardo, Owen Gallagher, and Xtine Burrough, eds. 2015. The Routledge Companion to Remix Studies. New York:

Routledge, Taylor \& Francis Group, p. 246.

Balasz Bodó and Gunkel, D J, 2005. Editorial: Introduction to hacking and hacktivism. New Media \& Society 7(5) 595-597.

Balasz Bodó, 2014. "Hacktivism 1-2-3: how privacy enhancing technologies change the face of anonymous hacktivism". Internet Policy Review, 3(4).

James Boyle, 1997. A politics of intellectual property: Environmentalism for the Net?. Duke Law Journal, 87-116.

James Boyle, 2003. The second enclosure movement and the construction of the public domain. Law and contemporary problems, 66(1/2), 33-74.

Sébastien Broca, 2013. Utopie du logiciel libre. Du bricolage informatique à la réinvention sociale, Neuvyen-Champagne, Le passager clandestin.

http://lepassagerclandestin.fr/fileadmin/assets/catalog/essais/Utopie_logiciel_libre_Broca_Le_pa ssager_clandestin.pdf

Sébastien Broca, 2016. "Épistémologie du code et imaginaire des « SHS 2.0 »", Variations, 19. http://variations.revues.org/701

Ian Brown and Chris Marsden, 2013. Regulating Code: Good Governance and Better Regulation in the Information Age, MIT Press/Cambridge. 
Patrick Burkart, 2014. Pirate Politics: The New Information Policy Contests. The Information Society Series. Cambridge, Mass: The MIT Press.

Valérie Cabanes, Proposal of Amendments to the International Criminal Court Rome Statute on the crime of Ecocide. End Ecocide Europe, 2015. https://www.endecocide.org/downloads/

Bart Cammaerts, 2008. Internet-mediated participation beyond the nation state Perspectives on democratic practice. Manchester University Press, Manchester, UK.

Bart Cammaerts, 2011. "Disruptive Sharing in a Digital Age: Rejecting Neoliberalism?", Continuum: Journal of Media and Cultural Studies, 25(1), pp.47-62.

Bart Cammaerts, 2015. "Pirates on the Liquid Shores of Liberal Democracy: Movement Frames of European Pirate Parties." Javnost - The Public 22 (1): 19-36.

Fritjof Capra and Ugo Mattei, 2015. The Ecology of Law: Toward a Legal System in Tune with Nature and Community, Berrett-Koehler Publishers.

Chiara Carrozza and Emanuele Fantini, 2016. "The Italian Water Movement and the Politics of the Commons." Water Alternatives 9, no. 1, p. 99-119. http://www.water-

alternatives.org/index.php/alldoc/articles/vol9/v9issue1/306-a9-1-5

Andrew Chadwick, 2007. 'Digital Network Repertoires and Organizational Hybridity', Political Communication, no. 24, p. 283-301. http://dx.doi.org/10.1080/10584600701471666

David Chavalarias, 2016. The unlikely encounter between von Foerster and Snowden: When second-order cybernetics sheds light on societal impacts of Big Data. Big Data \& Society, 3(1). http://doi.org/10.1177/2053951715621086

Katherine K. Chen, 2009. Enabling Creative Chaos: The Organization Behind the Burning Man Event, Chicago, IL: University of Chicago Press.

Gabriela Coleman, 2004. 'The Political Agnosticism of Free and Open Source Software and the Inadvertent Politics of Contrast', Anthropological Quarterly, 77, p. 507-19. http://dx.doi.org/10.1353/anq.2004.0035

Gabriela Coleman, 2012. Coding Freedom: The Ethics and Aesthetics of Hacking. New Haven, NJ: Princeton University Press.

Gabriela Coleman, 2014. Hacker, Hoaxer, Whistleblower, Spy: The Many Faces of Anonymous. London ; New York: Verso.

Danaher, J. (2014). Rule by Algorithm? Big Data and the Threat of Algocracy.

http://ieet.org/index.php/IEET/more/danaher20140107

John Danaher, 2016a, 'The Threat of Algocracy: Reality, Resistance and Accommodation', Philosophy \& Technology, 1-24.John Danaher, 2016b. 'Human Enhancement, Social Solidarity and the Distribution of Responsibility', Ethical Theory and Moral Practice, 19, p. 359-78.

Tine De Moor, 2011. "From Common Pastures to Global Commons: A Historical Perspective on Interdisciplinary Approaches to Commons." Natures Sciences Sociétés 19 (4): 422-31.

Jean-Pierre Digard, 2011. Horizon, trajets jazzistiques en anthropologie, L'Homme 1/2011 (n`197) , p. 111-138. www.cairn.info/revue-I-homme-2011-1-page-111.htm.

Raheleh B. Dilmaghani and Ramesh R. Rao. 2008. "Hybrid Wireless Mesh Network with Application to Emergency Scenarios." Journal of Software 3 (2).

Dixon, S. (2013), Discursive Intervention in International Intellectual Property Policymaking: How Developing Countries and Civil Society Employ Text to Challenge and Change the Status Quo. Communication, Culture \& Critique, 6: 598-615.

Dobusch Leonhard, Quack Sigrid (2008). Epistemic Communities and Social Movements: Transnational Dynamics in the Case of Creative Commons, MPIFG Discussion Paper 08/8. 
Melanie Dulong de Rosnay, 2013. "Open Content Licenses Without Representation: Can You Give Away More Rights Than You Have?", European Journal of Law and Technology, Vol. 4, No. 3. http://ejlt.org//article/view/237/410

Melanie Dulong de Rosnay, 2014. "The digital rights and access to knowledge movements: the rise of a networked do-ocracy", International Political Science Association (IPSA) conference, Montreal, July 2014.

Melanie Dulong de Rosnay, 2015. "Peer-to-Peer as a Design Principle for Law: Distribute the Law", Journal of Peer Production, issue 6, http://peerproduction.net/issues/issue-6-disruption-andthe-law/peer-reviewed-articles/peer-to-peer-as-a-design-principle-for-law-distribute-the-law/

Melanie Dulong de Rosnay and Francesca Musiani, 2016. "Towards a (De)centralization-Based Typology of Peer Production", TripleC: Communication, Capitalism \& Critique, Vol 14, No 1 (2016), pp. 189-207. http://www.triple-c.at/index.php/tripleC/article/view/728

Séverine Dusollier, 2006. The Master's Tools v. The Master's House: Creative Commons v. Copyright. Columbia Journal of Law \& Arts, 2006, vol. 29, pp. 271-293.

Séverine Dusollier, 2011. Scoping Study on Copyright and Related Rights and the Public Domain, CDIP/7/INF/2, Committee on Development and Intellectual Property of the World Intellectual Property Organisation. http://www.wipo.int/meetings/en/doc_details.jsp?doc_id=161162

Niva Elkin-Koren and Eli Salzberger, Law, Economics and Cyberspace: The Effects of Cyberspace on the Economic Analysis of Law, Edward Elgar, 2004.

Niva Elkin-Koren, 2006. Making technology visible: liability of internet service providers for peer-topeer traffic. New York University Journal of Legislation \& Public Policy 9(15): 15-76.

Niva Elkin-Koren, 2005. "What Contracts Cannot Do: The Limits of Private Ordering in facilitating a Creative Commons", Fordham Law Review 74(2): 375-422.

Haythem El Mekki, 2012. "Internet Activism, Tunisian Style", in Anya Schiffrin and Eamon Kircher-Allen (ed) From Cairo to Wall Street: Voices from the Global Spring, The New Press.

Estlund, D. (2003). Why Not Epistocracy? in Desire, Identity and Existence: Essays in honor of T. M. Penner, Academic Printing and Publishing.

Andrew Feenberg, 2014. "Vers une théorie critique de l'Internet" tic\&société, Vol. 8, № 1-2. http://ticetsociete.revues.org/1382 ; DOI : 10.4000/ticetsociete.1382

Edgar Fernández Fernández, Protection de l'environnement naturel et propriété privée, in Cedeño Bonilla, Marianela, Françoise Burhenne-Guilmin, and International Union for Conservation of Nature and Natural Resources, eds. 2004. Environmental Law in Developing Countries: Selected Issues. IUCN Environmental Policy and Law Paper, no. 43. Gland, Switzerland ; Bonn, Germany: IUCN, p. 43. https://portals.iucn.org/library/efiles/edocs/EPLP-043-2.pdf

Fitzpatrick, S. (2014). Setting Its Sights on the Marrakesh Treaty: The U.S. Role in Alleviating the Book Famine for Persons with Print Disabilities, Boston College International \& Comparative Law Review; Winter 2014, Vol. 37 Issue 1, p. 139.

http://lawdigitalcommons.bc.edu/cgi/viewcontent.cgi?article=1708\&context=iclr

Ann M. Florini and P. J. Simmons, What the World Needs Now? in Ann M. Florini, editor, The third force : the rise of transnational civil society, Carnegie Endowment for International Peace, 2000, $288 \mathrm{p}$.

Christian Fuchs, 2014. Social media and the public sphere. tripleC: Open Access Journal for a Global Sustainable Information Society, 12 (1). pp. 57-101. ISSN 1726-670X

Andrea Glorioso, Ugo Pagallo, and Giancarlo Ruffo, 2010. "The Social Impact of P2P Systems." In Handbook of Peer-to-Peer Networking, edited by Xuemin Shen, Heather Yu, John Buford, and Mursalin Akon, pp. 47-70. Boston, MA: Springer US.

Andrés Guadamuz, 2011. Networks, Complexity and Internet Regulation: Scale-Free Law. Cheltenham, UK ; Northampton, MA: Edward Elgar. 
Andrés Guadamuz, 2014. "Developments in Intermediary Liability" in Research Handbook On EU Internet Law, Andrej Savin and Jan Trzaskowski (eds), Edward Elgar, p. 312-336.

http://ssrn.com/abstract=2508253.

Andrés Guadamuz and Chris Marsden. 2015. "Blockchains and Bitcoin: Regulatory Responses to Cryptocurrencies." First Monday 20 (12).

Haas, P. M. (1992). Introduction: Epistemic Communities and International Policy Coordination. International Organization, Vol. 46, No. 1, Knowledge, Power, and International Policy Coordination. (Winter, 1992), pp. 1-35.

Jordan Hatcher (2007). "Mesh Networking: A look at the legal future". 11:5 Journal of Internet Law 1. http://ssrn.com/abstract=814984

Argyro P. Karanasiou and Emile Douilhet, 2016. "Never Mind the Data: The Legal Quest over Control of Information \&amp; the Networked Self," In: IEEE, pp. 100-105, and at http://ieeexplore.ieee.org/document/7527823/, accessed: 5 October 2016.

Machiel Karskens, 1997. "Law and Ground". In Marijan Pavcnik / Gianfrancesco Zanetti (ed.), Challenges to Law at the End of the 20th Century: Legal Systems and Legal Science. Proceedings of the 17th World Congress of the International Association for Philosophy of Law and Social Philosophy (IVR), Bologna, June 16-21, 1995. Vol. IV. Stuttgart: Franz Steiner Verlag 1997 (Archiv für Rechts- und Sozialphilosophie 70), p. 35-43. ISBN 3-515-07074-5.

Christopher M. Kelty, 2008. Two Bits: The Cultural Significance of Free Software. Duke University Press. http://twobits.net/pub/Kelty-TwoBits.pdf

Dmitry Kleiner, 2007. Copyfarleft and Copyjustright, http://www.metamute.org/editorial/articles/copyfarleft-and-copyjustright

Vasilis Kostakis, Vasilis Niaros, and Christos Giotitsas, 2015. 'Production and Governance in Hackerspaces: A Manifestation of Commons-Based Peer Production in the Physical Realm?', International Journal of Cultural Studies, Vol. 18, p. 555-73.

http://dx.doi.org/10.1177/1367877913519310

Alex Kreit, 2008. Vicarious Criminal Liability and the Constitutional Dimensions of Pinkerton, American University Law Review, Vol. 57, No. 3, p. 585, 2008. http://ssrn.com/abstract=1034289

Gaëlle Krikorian, Amy Kapczynski (ed.), 2010. Access to Knowledge in the Age of Intellectual Property, Zone Books.

Claire Lamine, Juliette Rouchier, 2014. D'une charte l'autre. Le processus de révision de la charte des AMAP comme indicateur d'une institution qui se renforce? (No. 1425). Aix-Marseille School of Economics, Marseille, France. http://econpapers.repec.org/paper/aimwpaimx/1425.htm

Lee, J. A., 2012. Nonprofit Organizations and the Intellectual Commons. Edward Elgar, Cheltenham, UK, National Chengchi University Legal Studies Series 73.

Lawrence Lessig, 1999a. 'The Law of the Horse: What Cyberlaw Might Teach', 113 Harvard Law Review pp. 501-546. https://cyber.law.harvard.edu/works/lessig/finalhls.pdf

Lawrence Lessig, 1999b. Code and Other Laws of Cyberspace, Basic books.

Jessica Litman, 2001. Digital Copyright, Prometheus books.

Alexandre Mallard, Cécile Méadel and Francesca Musiani, 2014. "The paradoxes of distributed trust: Peer-to-peer architecture and user confidence in Bitcoin," Journal of Peer Production, number 4. http://peerproduction.net/issues/issue-4-value-and-currency/peer-reviewed-articles/theparadoxes-of-distributed-trust/.

Robin Mansell, 2012. Imagining the Internet: Communication, Innovation, and Governance, Oxford University Press.

Chris Marsden, 2014. Law and technology, in Robin Mansell \& al (ed.), International Encyclopedia of Digital Communication \& Society, Wiley. http://ssrn.com/abstract=2416275 
Karl Marx, 1857. Grundrisse: Foundations of the Critique of Political Economy, Chapter 5 on Capital, Penguin Books in association with New Left Review, 1973, pp. 239-50.

https://www.marxists.org/archive/marx/works/1857/grundrisse/ch05.htm

Ugo Mattei, 2013. "Protecting the Commons: Water, Culture, and Nature: The Commons Movement in the Italian Struggle against Neoliberal Governance." South Atlantic Quarterly 112 (2): 366-76.

Jason Mazzone, 2011. Copyfraud and Other Abuses of Intellectual Property Law. Stanford, California: Stanford Law Books, an imprint of Stanford University Press.

Tomáš Minárik and Anna-Maria Osula, 2016. "Tor Does Not Stink: Use and Abuse of the Tor Anonymity Network from the Perspective of Law." Computer Law \& Security Review 32 (1): 11127.

Stefania Milan, 2013. Social Movements and Their Technologies: Wiring Social Change. Palgrave Macmillan.

Kathryn Milun, 2011. The Political Uncommons: The Cross-Cultural Logic of the Global Commons. Law, Justice and Power Series. Farnham, Surrey, England ; Burlington, VT: Ashgate.

Ministry of the Interior and Kingdom Relations, The Netherland 2013. Do-ocracy. A brief review of the Dutch Cabinet's policy document on facilitating a vibrant society. http://borderstocross.com/wpcontent/uploads/Do-ocracy-Handout-Borders-to-Cross.pdf

Mohler, G. O., Short, M. B., Brantingham, P. J., Schoenberg, F. P., \& Tita, G. E., 2011. SelfExciting Point Process Modeling of Crime. Journal of the American Statistical Association, Vol. 106(493), p. 100-108. http://doi.org/10.1198/jasa.2011.ap09546

Patrick Mundler, 2007. « Les Associations pour le maintien de l'agriculture paysanne (AMAP) en Rhône-Alpes, entre marché et solidarité ", Ruralia, 20. http://ruralia.revues.org/1702

Andrew Murray, The Regulation of Cyberspace: Control in the Online Environment, RoutledgeCavendish, 2006.

Francesca Musiani, 2014. "Decentralised internet governance: the case of a "peer-to-peer cloud". Internet Policy Review, 3(1). http://policyreview.info/articles/analysis/decentralised-internetgovernance-case-peer-peer-cloud

Francesca Musiani, 2015. Giants, Dwarfs and Decentralized Alternatives to Internet-based Services: An Issue of Internet Governance. Westminster Papers in Communication and Culture. 10(1), pp.81-94. http://www.westminsterpapers.org/articles/10.16997/wpcc.214/

Axel Neumann, Ester López, and Leandro Navarro, 2015. "Evaluation of Mesh Routing Protocols for Wireless Community Networks." Computer Networks 93: 308-23.

Quinn Norton. "How Anonymous Picks Targets, Launches Attacks, and Takes Powerful Organizations Down" Wired, July 2012.

Aral Oram (Ed.) (2001). Peer-to-peer: Harnessing the Power of Disruptive Technologies. Sebastopol, CA: O'Reilly.

Elinor Ostrom, 1990. Governing the Commons. The Evolution of Institutions for Collective Action, Cambridge University Press: Cambridge.

Jessica Owley, "Property Constructs and Nature's Challenge to Perpetuity" in Hirokawa, Keith H., ed. 2014. Environmental Law and Contrasting Ideas of Nature: A Constructivist Approach. New York, NY: Cambridge University Press, p. 64.

Rachel Polaud, 2012. L'implication des ONG dans les débats des OIG : le cas de l'aménagement des droits de propriété intellectuelle par l'OMC, l'OMS, l'OMPI entre 1996 et 2006, Thèse de sciences politiques, Université de Grenoble, 2012, 301 p.

Hector Postigo, 2012. The Digital Rights Movement: The Role of Technology in Subverting Digital Copyright. The Information Society Series. Cambridge, Mass: The MIT Press.

John Postill, 2014. 'Freedom Technologists and the New Protest Movements: A Theory of Protest Formulas', Convergence: The International Journal of Research into New Media Technologies, No 
20, p. 402-18. http://dx.doi.org/10.1177/1354856514541350

Alison Powell, 2016a. "Hacking in the public interest: authority, legitimacy, means and ends". New Media and Society. 18 (4) pp. 600-616.

Alison Powell, 2016b. "Network Exceptionalism: Online Action, Discourse and the Opposition to SOPA and ACTA." Information, Communication \& Society 19 (2): 249-63. doi:10.1080/1369118X.2015.1061572.

Denis Roio, Marco Sachy, Stefano Lucarelli, Bernard Lietaer, Francesca Bria, 2015. Deliverable 4.4 Design of Social Digital Currency, Deliverable of the European project D-CENT. Decentralised Citizens ENgagement Technologies.

http://www.nesta.org.uk/sites/default/files/design_of_social_digital_currency.pdf

Antoinette Rouvroy. "The end(s) of critique : data-behaviourism vs. due-process." in Privacy, Due Process and the Computational Turn. Ed. Mireille Hildebrandt, Ekatarina De Vries, Routledge, 2012. Available at: http://works.bepress.com/antoinette_rouvroy/44

Douglas Rushkoff, 2003. Open source democracy: How online communication is changing offline politics. London: Demos. http://rushkoff.com/books/open-source-democracy

Giovanni Sartor, 2009. Cognitive automata and the law: electronic contracting and the intentionality of software agents, Artificial intelligence and law 17 (4), pp. 253-290.

Rüdiger Schollmeier, 2001. 'A definition of peer-to-peer networking for the classification of peer-topeer architectures and applications', Proceedings of the First International Conference on Peer-toPeer Computing, IEEE, pp. 27-29.

http://www.computer.org/csdl/proceedings/p2p/2001/1503/00/15030101.pdf

Marion Smiley, 2011. 'Collective Responsibility', in Edward N. Zalta (ed) The Stanford Encyclopedia of Philosophy. http://plato.stanford.edu/archives/fall2011/entries/collectiveresponsibility/

Johan Söderberg, 2008). Hacking capitalism: The free and open source software movement. London, Routledge.

Maximilian Steinbeis, 2012. 'Occupy the Law!', report of the Conference on Transnational Societal Constitutionalism, Frankfurter Allgemeine Zeitung and VerfBlog.

http://www.verfassungsblog.de/occupy-law

Stone, D. (2008) Global public policy, transnational policy communities, and their networks. Policy Studies Journal, Vol.36 (No.1). pp. 19-38.

Günther Teubner, 2006. 'Rights of Non-Humans? Electronic Agents and Animals as New Actors in Politics and Law, Journal of Law and Society, Vol. 33(4), pp. 497-521.

Javier Toret and Antonio Calleja, 2014. Collective Intelligence Framework. Deliverable D2.1, DCent European project, 81 p. http://dcentproject.eu/wpcontent/uploads/2015/10/collective_intelligence_framework.pdf

Félix Tréguer, 2014. Hacker l'espace public : la citoyenneté insurrectionnelle sur Internet, Tracés. Revue de Sciences humaines. p. 129-147.

Nathaniel Tkacz, 2012. From open source to open government : a critique of open politics. Ephemera: Theory and Politics in Organization, Vol.12 (No.4). pp. 386-405.

David Unterhalter, 1988. Doctrine of Common Purpose: What Makes One Person Liable for the Acts of Another, South African Law Journal, Vol. 105, p. 671.

Siva Vaidhyanathan, 2005. The Anarchist in the Library. Basic Books.

Imrat Verhoeven, Tamara Metze \& Ted van de Wijdeven, 2014. Do-ocracy's democratic anchorage, Conference European Consortium for Political Research (ECPR) Joint Sessions of Workshops, Salamanca, Workshop on Systematising Comparison of Democratic Innovations: Advanced Explanations of the Emergence, Sustenance and Failure of Participatory Institutions. 
Miguel Viera and Primavera De Filippi, 2014. "Between Copyleft and Copyfarleft: Advance Reciprocity for the Commons". Journal of Peer Production, 4.

Abdulrahman Yarali, Babak Ahsant and Saifur Rahman, 2009. "Wireless mesh networking: A key solution for emergency \& rural applications", MESH 2009. Proceedings of the Second International Conference on Advances in Mesh Networks, IEEE, p. 143-149.

http://doi.ieeecomputersociety.org/10.1109/MESH.2009.33

Jonathan Zittrain (2006). A History of Online Gatekeeping. Harvard Journal of Law \& Technology, 19 (2), p. 253-298. 